\title{
Synergistic effect of pedalitin and amphotericin B against Cryptococcus neoformans by in vitro and in vivo evaluation
}

\author{
Fernanda Sangalli-Leite a , Liliana Scorzoni a , Ana Carolina Alves de Paula e Silva a \\ Julhiany de Fátima da Silva a , Haroldo Cesar de Oliveira a , Junya de Lacorte Singulani a , \\ Fernanda Patrícia Gullo a, Rosangela Moraes da Silva a , Luis Octávio Regasini ${ }^{\text {b }}$, \\ Dulce Helena Siqueira da Silva ${ }^{\text {b }}$, Vanderlan da Silva Bolzani ${ }^{\text {b }}$, \\ Ana Marisa Fusco-Almeida a , Maria José Soares Mendes-Giannini a,* \\ a Faculdade de Ciências Farmacêuticas de Araraquara, Universidade Estadual Paulista (UNESP), Departamento de Análises Clínicas, \\ Laboratório de Micologia Clínica, Araraquara, Brazil \\ b Instituto de Química, Universidade Estadual Paulista (UNESP), Araraquara, Brazil
}

\section{A R T I C L E I N F O}

\section{Article history:}

Received 2 May 2016

Accepted 30 July 2016

\section{Keywords:}

Cryptococcus neoformans

Pedalitin

Amphotericin B

Chequerboard

Galleria mellonella

\begin{abstract}
A B S T R A C T
Cryptococcosis is an opportunistic fungal infection responsible for high morbidity and mortality in immunocompromised patients. Combination of antifungal substances is a promising way to increase the percentage of successful treatment. Pedalitin (PED) is a natural substance obtained from Pterogyne nitens. The aim of this study was to verify the efficacy of PED alone and in combination with amphotericin B $(\mathrm{AmB})$ in vitro and in vivo against Cryptococcus spp. In the in vitro assay, minimum inhibitory concentrations (MICs) of $0.125 \mathrm{mg} / \mathrm{L}$ for $\mathrm{AmB}$ and $3.9 \mathrm{mg} / \mathrm{L}$ for PED were found when the substances were tested alone, whilst in the combination treatment the active concentration of both decreased, with MICs of $0.03 \mathrm{mg} / \mathrm{L}$ for AmB and $1 \mathrm{mg} / \mathrm{L}$ for PED. In the survival assay, fungal burden study and histopathological assays it was possible to study the efficacy of the substances alone and in combination. The efficacy of combination therapy was considered better than monotherapy as evaluated in a Galleria mellonella model and a murine model. Thus, the combination of PED and AmB is an interesting alternative for anticryptococcal fungal treatment. Moreover, a correlation was observed between the invertebrate and murine models for this antifungal treatment combination.
\end{abstract}

(c) 2016 Elsevier B.V. and International Society of Chemotherapy. All rights reserved.

\section{Introduction}

Cryptococcus neoformans and Cryptococcus gattii are the main pathogenic species causing cryptococcosis, an opportunistic fungal infection caused by inhaling basidiospores or dissected yeasts present in the environment, affecting the respiratory tract of the host and causing severe pneumonia and respiratory insufficiency $[1,2]$. Cryptococcosis mainly affects immunocompromised patients, in whom the yeast can reach other sites of infection such as the central nervous system, causing meningitis and meningoencephalitis. Cryptococcosis is responsible for high morbidity and mortality in human immunodeficiency virus (HIV)-infected patients [3-5].

Therapy for cryptococcosis comprises the combination of 5-flucytosine and amphotericin $B(A m B)$, which presents high toxicity. Maintenance therapy is recommended with fluconazole, but

\footnotetext{
* Corresponding author. Rodovia Araraquara-Jaú Km 1, CEP: 14801-902, Araraquara, São Paulo, Brazil.

E-mail address: giannini@fcfar.unesp.br (M.J. Soares Mendes-Giannini).
}

the development of resistant strains has been described [6-8]. Natural substances have been shown to be an interesting alternative in the search for new antifungals, serving as templates for the synthesis of new compounds with fewer side effects and better biological activity [9].

Pterogyne nitens belongs to the family Fabaceae and is found distributed from the northeast to the south of Brazil as well as in Paraguay, Bolivia and Argentina. The crude extract of its leaves has been studied, culminating in the isolation and characterisation of various pure substances, including the flavonoid pedalitin (PED) [10]. Chromatographic (gel permeation chromatography and highperformance liquid chromatography) and spectroscopic [nuclear magnetic resonance (NMR)] techniques were carried out with crude extract of the leaves of $P$. nitens to afford the isolation and characterisation of the flavonoids kaempferol, afzelin, lespedin or kaempferitrin, pteroginoside, quercetin and isoquercetin and the flavone PED [11]. The PED structure was elucidated by NMR spectrometry and high-resolution mass spectrometry [12].

Combination of antifungal substances is a promising way to increase the percentage of successful treatment [13]. In vitro data showed that low doses of AmB might be used in combination with 
voriconazole without resulting in decreased clinical response [14]. The drugs used in cryptococcosis treatment are being widely investigated to find the best combination with high efficiency, reduced resistance development, reduced toxicity and shorter duration of therapy [15].

Because of ethical issues, scientists need to find alternative animal tests that can be used for screening and only subsequently use mammalian models in more focused studies, minimising the number of animals used [16]. Invertebrate animal models are valuable tools in different approaches. Galleria mellonella is a useful model to evaluate virulence as well as efficacy and toxicity of antifungal drugs. Studies using G. mellonella and Cryptococcus yeast are increasing, and there are reports on the use of this invertebrate model to study virulence and the efficacy of antifungal therapy against Cryptococcus $[17,18]$. Thus, the use of an alternative animal model is an option in the search for new natural antifungal compounds, allowing screening for their toxicity and efficacy before launching more targeted studies with mammalian models.

The aim of this study was to demonstrate the in vitro antifungal activity of PED and its synergistic effect with AmB and, moreover, to verify the efficacy of the synergistic combination of PED and AmB in vivo using the alternative animal model $G$. mellonella first for screening, followed by correlation with a mammalian model.

\section{Materials and methods}

\subsection{Pedalitin and antifungal agent}

PED was provided by Chemical Institute-UNESP (Araraquara, Brazil) and AmB was from Sigma-Aldrich (St Louis, MO).

\subsection{Fungal culture and inoculum}

Cryptococcus neoformans strain ATCC 90112 was maintained in Sabouraud agar (Difco Laboratories, Detroit, MI) at $37^{\circ} \mathrm{C}$. For the experiments, the yeast was cultivated in Sabouraud broth (Difco) at $37{ }^{\circ} \mathrm{C}(150 \mathrm{rpm})$ for $24 \mathrm{~h}$.

\subsection{Susceptibility testing}

The microdilution method described by the Clinical and Laboratory Standards Institute (CLSI) [19] with modifications [20] was used to determine the minimum inhibitory concentration (MIC), which was assessed visually as the lowest concentration between 0.48 and $250 \mathrm{mg} / \mathrm{L}$ that inhibited visible growth. Plates were incubated at $37{ }^{\circ} \mathrm{C}(150 \mathrm{rpm})$ for $48 \mathrm{~h}$.

The minimum fungicidal concentration (MFC) was determined by transferring an aliquot to a Sabouraud agar plate (SigmaAldrich) plus $100 \mathrm{mg} / \mathrm{mL}$ ampicillin (Sigma-Aldrich), which was incubated at $37^{\circ} \mathrm{C}$ for $48 \mathrm{~h}$. The MFC was determined as the lowest concentration of the compound that did not permit visual fungal growth.

\subsection{Chequerboard assays}

The interaction of the compounds was assessed by the chequerboard broth microdilution method [21,22]. Each compound and/or antifungal agent four times more concentrated than the final concentration was dispensed following the conditions used in the microdilution test. The compounds were also tested alone. The combinatorial test result was the lowest concentration of each combination that completely inhibited sample growth.

The fractional inhibitory concentration index (FICI) was calculated using the equation: $\Sigma \mathrm{FIC}=\mathrm{FIC}_{\mathrm{A}}+\mathrm{FIC}_{\mathrm{B}}$, where the FIC is the ratio of the MIC of the drug in combination with the MIC alone [21,22]. A combination was considered synergistic at an $\mathrm{FICI} \leq 0.5$, indiffer- ent at $\mathrm{FICI}>1$ and $\leq 4$ and antagonistic at $\mathrm{FICI}>4.0$. The same formula was used to calculate the fractional fungicidal concentration index (FFCI), using MFC values instead of MIC [22].

\subsection{Cryptococcus neoformans time-kill assay}

Cryptococcus neoformans $\left(5 \times 10^{5}\right.$ cells/well) was treated with PED at $4 \mathrm{mg} / \mathrm{L}, A m B$ at $0.125 \mathrm{mg} / \mathrm{L}$ and the combination of PED at $1 \mathrm{mg} / \mathrm{L}$ and $\mathrm{AmB}$ at $0.03 \mathrm{mg} / \mathrm{L}$ for $0,0.5,1,2,4,8,10,12,24$ and $48 \mathrm{~h}$ at $37^{\circ} \mathrm{C}$. The suspensions were inoculated on Sabouraud agar plates supplemented with $100 \mathrm{mg} / \mathrm{mL}$ ampicillin and were incubated at $37^{\circ} \mathrm{C}$ for $48 \mathrm{~h}$. The number of CFU was determined by estimating the decrease in viable cell number after different times in contact with the different treatments.

\subsection{Cell culture}

The tumoural cell lineages U87-MG (human glioblastoma) and HepG-2 (human hepatoma) as well as MRC-5 (human pulmonary fibroblast), which were obtained from the Rio de Janeiro cell bank, and the lineage NOK (keratinocyte oral mucosa), which was donated by Dr Karl Munger (Department of Medicine, Harvard Medical School, Boston, MA) were used. Cells were cultivated in Dulbecco's Modified Eagle Medium (DMEM) (Sigma-Aldrich) supplemented with 10\% heat-inactivated foetal bovine serum at $37^{\circ} \mathrm{C}$ in a $5 \% \mathrm{CO}_{2}$ atmosphere.

\subsubsection{Cytotoxicity assay using MTT}

The cell monolayer formed was exposed to concentrations of the compounds in the range $0.12-62.5 \mathrm{mg} / \mathrm{L}$ for $24 \mathrm{~h}$. The MTT method was performed using 3-(4,5-dimethyl-2-thiazolyl)-2,5-diphenyl$2 \mathrm{H}$-tretazolium bromide (Sigma-Aldrich) at $5 \mathrm{mg} / \mathrm{mL}$. Untreated cells (viable cells) and cells treated with hydrogen peroxide (SigmaAldrich) (dead cells) were used as controls. The $\mathrm{IC}_{50}$ values indicate the concentration at which $50 \%$ of the cells were killed.

The selective index (SI) was calculated using the equation $\mathrm{SI}=\mathrm{IC}_{50} /$ MFC [23]. Compounds with SI values $\geq 10$ were considered to be more active against the yeast and less cytotoxic to the host, which is indispensable for treatment safety [24].

\subsubsection{Influence of antifungal treatment on infection with Cryptococcus neoformans in cell culture}

U87-MG and MRC-5 cell lineages $\left(1 \times 10^{5}\right.$ cells/well $)$ were infected with $C$. neoformans $\left(2.5 \times 10^{4}\right.$ cells/well $)$ and were incubated at $37^{\circ} \mathrm{C}$ ( $4 \mathrm{~h}$ for MRC- 5 cell lineage and $1 \mathrm{~h}$ for U87-MG cell lineage). The wells were washed twice with phosphate-buffered saline (PBS) and were treated with PED at $4 \mathrm{mg} / \mathrm{L}, A m B$ at $0.125 \mathrm{mg} / \mathrm{L}$ and the combination of PED at $1 \mathrm{mg} / \mathrm{L}+\mathrm{AmB} 0.03 \mathrm{mg} / \mathrm{L}$. According to the time-kill assay, the incubation times were $30 \mathrm{~min}, 1 \mathrm{~h}$ and $2 \mathrm{~h}$ at $37^{\circ} \mathrm{C}$. Following treatment, the wells were washed twice with PBS, were subjected to trypsin treatment and were inoculated on Sabouraud plates supplemented with $100 \mathrm{mg} / \mathrm{mL}$ ampicillin. After $48 \mathrm{~h}$ at $37^{\circ} \mathrm{C}$, the percentage of CFU in each situation was determined.

\subsection{Galleria mellonella growth and experimental conditions}

Galleria mellonella was maintained and grown in the laboratory. The larval phase of $G$. mellonella was fed with wax and pollen and was maintained at $28^{\circ} \mathrm{C}$. For the experiments, control and treatment larvae weighing $150-200 \mathrm{mg}$ and without colour alterations were selected and were incubated at $37^{\circ} \mathrm{C}$ overnight, protected from light and without food. Before the experiment, the pro-leg region was cleaned with $70 \%$ ethanol. For the inoculation, a Hamilton syringe (Hamilton Co., Reno, NV) was used to inject $10 \mu \mathrm{L}$ of inoculum and/or treatment solution through the last left larvae proleg. The control groups were untouched larvae and larvae injected 
with PBS. Larvae were incubated at $37^{\circ} \mathrm{C}$ and death was monitored daily for 7 days by visual inspection based on lack of movement after touching with forceps. Each experiment was repeated at least three times with 16 larvae for each condition.

\subsubsection{Toxicity assay}

Larvae were injected with dimethyl sulphoxide (DMSO) $(5 \%, 10 \%$ and 20\%), AmB (0.5, 1, 2 and $4 \mathrm{mg} / \mathrm{kg})$ and PED $(6.25,12.5,25,40$, 50,100 and $200 \mathrm{mg} / \mathrm{kg}$ ) and were incubated at $37^{\circ} \mathrm{C}$ for 7 days. Death was monitored by visual inspection based on lack of movement after touching. The AmB doses used were in accordance with therapeutic doses recommended by cryptococcal clinical guidelines [6], and PED doses were calculated considering the MIC and the larval weight. The doses were increased to determine the toxicity of the substance.

\subsubsection{Cryptococcus neoformans survival curve}

Three fungal concentrations were used to determine the ideal inoculum concentration able to kill the larvae within 7 days of the experiment $\left(5 \times 10^{6}, 1 \times 10^{6}\right.$ and $5 \times 10^{5}$ cells/larvae $)$ at $37^{\circ} \mathrm{C}$, evaluating survival daily. The experiment time was considered appropriate for this model because of the insect life cycle.

\subsection{Treatment efficacy in Galleria mellonella infected with Cryptococcus neoformans}

\subsubsection{Survival time}

Larvae were infected with $C$. neoformans $\left(1 \times 10^{6}\right.$ cells/larvae) and then $1 \mathrm{~h}$ later the following treatments were conducted: AmB doses of $0.5,1,2$ and $4 \mathrm{mg} / \mathrm{kg}$; PED at 6.25, 1.5, 25, 40, 50, 100 and $200 \mathrm{mg} /$ $\mathrm{kg}$; and the combination of AmB $0.3 \mathrm{mg} / \mathrm{kg}+$ PED $10 \mathrm{mg} / \mathrm{kg}$.

\subsubsection{Fungal burden}

Three larvae from each group, i.e. untreated and treated with AmB $4 \mathrm{mg} / \mathrm{kg}$, PED $40 \mathrm{mg} / \mathrm{kg}$ and the synergistic dose of AmB $0.3 \mathrm{mg} /$ $\mathrm{kg}+$ PED $10 \mathrm{mg} / \mathrm{kg}$, were collected during Days 0 to 3 of the experiment. Larvae were sliced, were mixed in PBS with glass beads, and different dilutions were plated on Sabouraud plates supplemented with $100 \mathrm{mg} / \mathrm{mL}$ ampicillin. After $48 \mathrm{~h}$ at $37^{\circ} \mathrm{C}$, the CFU percentage of each situation was evaluated to determine efficacy.

\subsubsection{Histopathological analysis}

Three larvae in each group, i.e. untreated and treated with AmB $4 \mathrm{mg} / \mathrm{kg}$, PED $40 \mathrm{mg} / \mathrm{kg}$ and the synergistic dose of AmB $0.3 \mathrm{mg} /$ $\mathrm{kg}+$ PED $10 \mathrm{mg} / \mathrm{kg}$, were collected at times 0, 1, 2 and 3 days. The larvae were fixed in $10 \%$ formalin for $24 \mathrm{~h}$ and were dehydrated with increasing concentrations of ethanol, were washed with xylol and, finally, were embedded in paraffin. They were sectioned serially at a thickness of $5 \mu \mathrm{m}$ and were stained using Periodic acid-Schiff. The images were analysed using an optical microscope with a $40 \times$ objective.

\subsection{Rearing of $B A L B / C$ mice and experimental conditions}

All animal protocols were approved and performed in accordance with the guidelines established by the Institutional Animal Care and Use Committee of the Faculdade de Ciências Farmacêuticas, Universidade Estadual Paulista (UNESP) (Araraquara, Brazil). BALB/c mice were anaesthetised with ketamine/xylazine $(80 / 10 \mathrm{mg} / \mathrm{kg})$. Animals were inoculated intratracheally with $50 \mu \mathrm{L}$ of $5 \times 10^{6}$ yeast cells/mL and survival was monitored daily.

\subsection{Treatment assay in $B A L B / c$ mice infected with Cryptococcus neoformans}

\subsubsection{Survival time}

Infected animals were treated intraperitoneally daily for 40 days with AmB $1 \mathrm{mg} / \mathrm{kg}$, PED $40 \mathrm{mg} / \mathrm{kg}$ or the combination treatment of AmB $0.3 \mathrm{mg} / \mathrm{kg}+\mathrm{PED} 10 \mathrm{mg} / \mathrm{kg}$. To determine the survival time, the animals were checked daily. The toxicity of these doses was evaluated (data not shown).

\subsubsection{Fungal burden}

Lungs and brain were excised after 7 days and 14 days and were homogenised in PBS using a tissue grinder [25]. The suspension was plated on Sabouraud plates supplemented with $100 \mathrm{mg} / \mathrm{mL}$ ampicillin and was incubated at $37^{\circ} \mathrm{C}$ for $48 \mathrm{~h}$. The CFU/organ of each condition was evaluated.

\subsubsection{Histopathological assay}

Lungs were excised from mice after 14 days of treatment and were fixed in formalin for $48 \mathrm{~h}$ at room temperature. The tissues were dehydrated and were embedded in paraffin. Tissue sections were stained with haematoxylin and eosin. The images were analysed under an optical microscope with a $20 \times$ objective.

\subsection{Statistical analysis}

All statistical analyses were performed using GraphPad Prism (GraphPad Software Inc., La Jolla, CA). The representative graphics of treatment of infection by $C$. neoformans in cell culture and cytotoxicity was analysed by two-way analysis of variance (ANOVA) with multiple comparison by Bonferroni post-test. Survival curves were analysed by log-rank (Mantel-Cox) test. Fungal burden was analysed using the $t$-test. A $P$-value of $<0.05$ was considered statistically significant.

\section{Results}

\subsection{In vitro antifungal activity and cytotoxicity}

Table 1 shows the MIC and MFC values of PED as well as PED in combination with AmB. The MFC was equal to the MIC for the antifungal combination. The combinations tested decreased the MIC value by four-fold compared with AmB and PED. The FICI and FFCI values were considered promising, showing a synergistic effect. In the evaluation of compound safety, PED presented $\mathrm{IC}_{50}$ values higher than the MIC and MFC values found in the susceptibility test. PED

\section{Table 1}

Susceptibility values of pedalitin (PED) and amphotericin B (AmB) alone and in combination against Cryptococcus spp., and selectivity index and $\mathrm{IC}_{50}$ values of PED in different cell lines.

\begin{tabular}{llll}
\hline Susceptibility test & Chequerboard assay & & \\
\hline MIC/MFC & MIC ${ }^{\mathrm{a}}$ (AmB/PED) & FICI/effect & $\begin{array}{l}\text { FFCI/effect } \\
0.49 / \text { Syn }\end{array}$ \\
$\begin{array}{l}\text { AmB, 0.125/0.125 } \\
\text { PED, 3.9/3.9 }\end{array}$ & $0.03 / 1$ & NOK & U87-MG \\
$\begin{array}{l}\text { HepG2 } \\
\text { Selectivity index }\end{array}$ & MRC-5 & & \\
$\begin{array}{l}33.7 \\
\text { IC } 50 \text { (mg/L) }\end{array}$ & 49.1 & 30.5 & 44.9 \\
HepG2 & & & \\
131.7 & MRC-5 & NOK & U87-MG \\
\hline
\end{tabular}

MIC, minimum inhibitory concentration; MFC, minimum fungicidal concentration; FICI, fractional inhibitory concentration index; FFCI, fractional fungicidal concentration index; Syn, synergistic; $\mathrm{IC}_{50}$, concentration at which $50 \%$ of the cells were killed; HepG2, human hepatoma; MRC-5, human pulmonary fibroblast; NOK, keratinocyte oral mucosa; U87-MG, human glioblastoma.

a $\mathrm{MIC}$ in the combination $(\mathrm{mg} / \mathrm{L})$. 


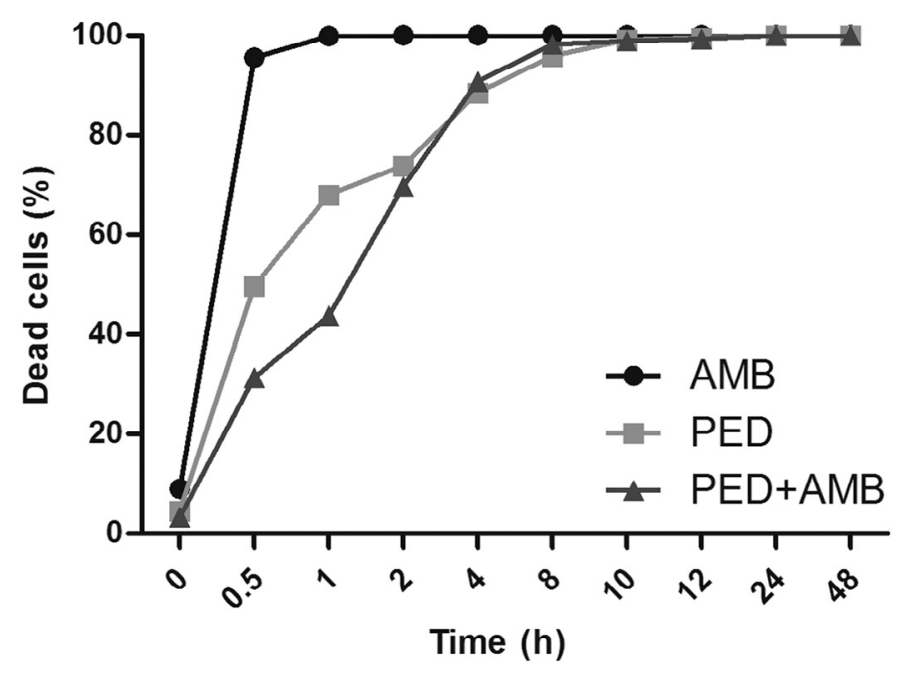

Fig. 1. Time-kill analysis of Cryptococcus neoformans. Cryptococcus neoformans was treated with $0.125 \mathrm{mg} / \mathrm{L}$ amphotericin $\mathrm{B}(\mathrm{AmB}), 4 \mathrm{mg} / \mathrm{L}$ pedalitin (PED) and a synergistic combination ( $1 \mathrm{mg} / \mathrm{L}$ PED $+0.03 \mathrm{mg} / \mathrm{L} \mathrm{AmB}$ ) and death was observed in relation to contact time $(0,0.5,1,2,4,8,10,12,24$ and $48 \mathrm{~h})$. Rates are representative of the percentage of dead cells referring to the mean count of CFU after plating.

showed the highest $\mathrm{IC}_{50}$ value for all the cell types; moreover, SI values of $\geq 10$ were found.

\subsection{Cryptococcus neoformans in vitro time-kill assay}

AmB at $0.125 \mathrm{mg} / \mathrm{L}$ showed strong activity, with $>95 \%$ killing in 30 min of contact with C. neoformans. Treatment with PED at $4 \mathrm{mg} / \mathrm{L}$ killed $50 \%$ of the yeast cells in $30 \mathrm{~min}$ and $100 \%$ after $8 \mathrm{~h}$. The combined treatment (AmB $0.03 \mathrm{mg} / \mathrm{L}+$ PED $1 \mathrm{mg} / \mathrm{L}$ ) killed a high number of yeast cells within $30 \mathrm{~min}$ (31\%) and >98\% after 8 h (Fig. 1).

\subsection{Influence of synergistic treatment in infection by Cryptococcus neoformans in cell culture}

A significant reduction in infection was observed at all times $(P<0.05)$. After $30 \mathrm{~min}, 50 \%$ reduction in infection was observed with the treatments in both cell types assayed. After $2 \mathrm{~h}$ of treatment, $60 \%$ and $40 \%$ infection levels were observed in lung fibroblasts and in glioblastoma cells, respectively. Comparing treatments with AmB and PED showed significant differences at $30 \mathrm{~min}(P<0.05)$, whilst similar activity of these two compounds was observed after $1 \mathrm{~h}$ and $2 \mathrm{~h}$. When the data of PED were compared with the synergistic combination, there was difference just at 30 min for glioblastoma cells $(P<0.05)$ (Fig. 2). AmB and the synergistic combination were different just for lung fibroblasts at $30 \mathrm{~min}(P<0.05)$.

\subsection{Efficacy of treatment with pedalitin alone and combined with amphotericin B in a Galleria mellonella model}

\subsubsection{Survival curve of Cryptococcus neoformans}

The fungal suspension of $1 \times 10^{6}$ cells/larvae was chosen for the following tests. On Days 2, 3 and 4, 75\%, 25\% and 0\% of the larvae were alive, respectively (Fig. 3A).

\subsubsection{Toxicity assay of diluents and substances}

The DMSO concentration used was $5 \%$ for solubilisation of agents, as higher concentrations caused larval death. For AmB, no tested doses showed toxicity (100\% survival). For PED, toxicity was not observed below $40 \mathrm{mg} / \mathrm{kg}$; however, there was a high larval mortality rate between $50 \mathrm{mg} / \mathrm{kg}$ and $200 \mathrm{mg} / \mathrm{kg}$ (Fig. 3B).

\subsubsection{Efficacy of synergistic treatment}

All of the AmB doses (1, 2 and $4 \mathrm{mg} / \mathrm{kg}$ ) increased larvae survival $(P<0.05)$ (Fig. 4 ). The dose of $4 \mathrm{mg} / \mathrm{kg}$ was selected as a control for the subsequent experiments. Regarding PED, all of the doses (6.25, $12.5,25$ and $40 \mathrm{mg} / \mathrm{kg}$ ) were able to increase the survival of infected larvae $(P<0.05)$; however, the dose with the highest survival percentage was $40 \mathrm{mg} / \mathrm{kg}$. At this dose, $37 \%$ of the larvae were alive at the end of the experiment (Fig. 4B). To evaluate the synergistic efficacy in vivo, the antifungal combination of $0.3 \mathrm{mg} / \mathrm{kg} \mathrm{AmB} \mathrm{+}$ $10 \mathrm{mg} / \mathrm{kg}$ PED, as well as the substances alone at the same dose, were evaluated. Treatment with $0.3 \mathrm{mg} / \mathrm{kg}$ AmB led to $50 \%$ and $18.7 \%$ survival of larvae on the fifth and sixth days of the experiment. When analysing $10 \mathrm{mg} / \mathrm{kg}$ PED treatment, 26\% and 0\% survival of larvae was observed on the fifth and sixth days of the experiment. However, for the combination treatment, $>56 \%$ of larvae were alive at the end of the experiment (Fig. 4C).

There was large decrease in C. neoformans CFUs treated with AmB ( $4.0 \mathrm{mg} / \mathrm{kg})$, PED (40 mg/kg) and the combination of the two substances (AmB $0.3 \mathrm{mg} / \mathrm{kg}$ + PED $10 \mathrm{mg} / \mathrm{kg}$ ). On Day 1, reductions of $88 \%, 87 \%$ and $93 \%$ were observed after treatment with AmB, PED or the combination therapy, respectively, and on Day 4 there was almost $100 \%$ reduction of the fungal burden (Fig. 4D-F).

Finally, the efficacy of the synergism was observed by histopathology of larvae from Days 0 to 3. Severe tissue destruction and
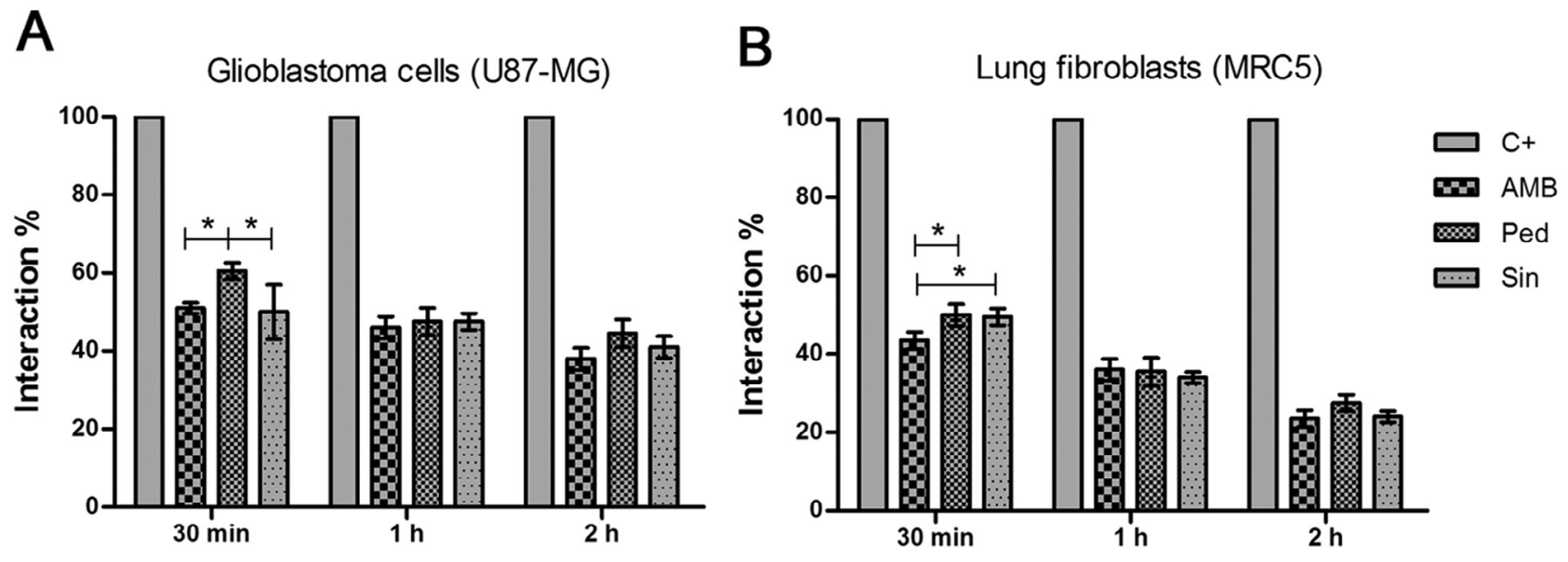

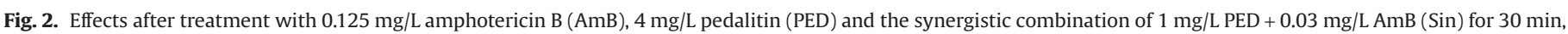
$1 \mathrm{~h}$ and $2 \mathrm{~h}$ in (A) U87-MG and (B) MRC-5 cells infected with Cryptococcus neoformans. ${ }^{*} P<0.05$. 

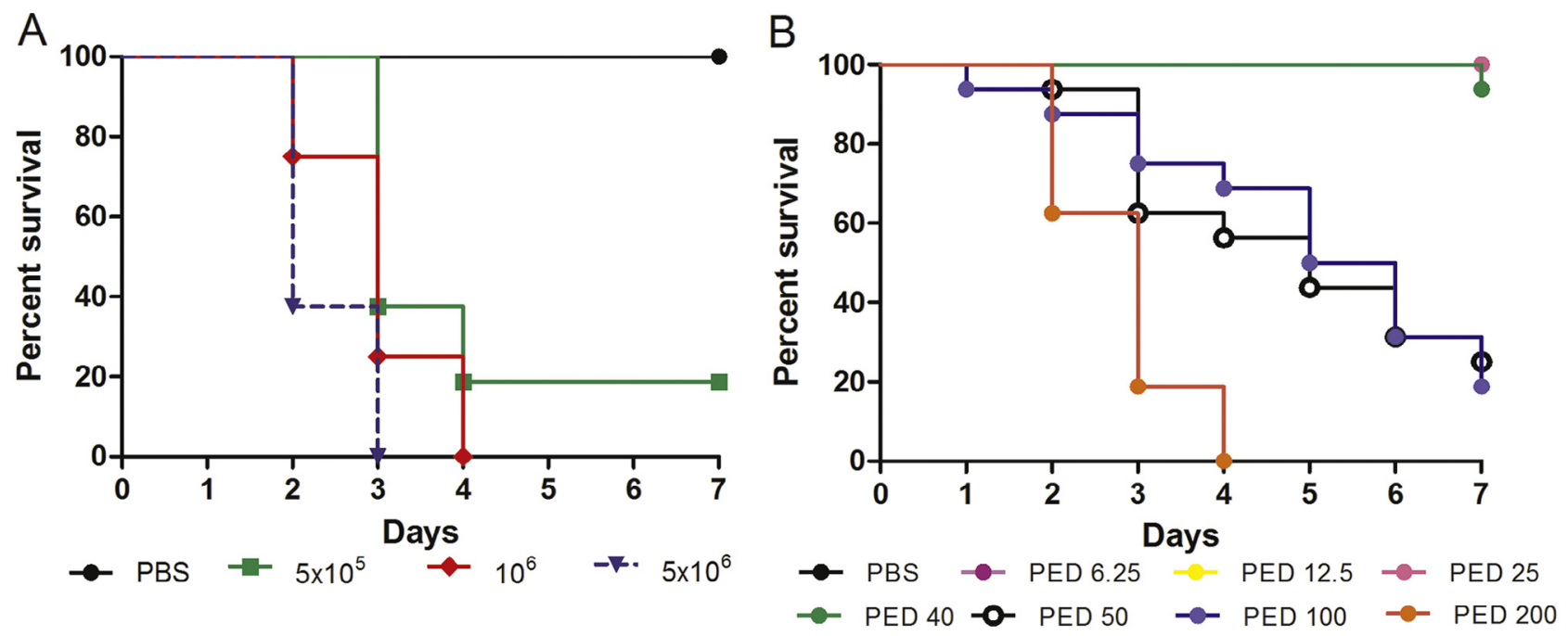

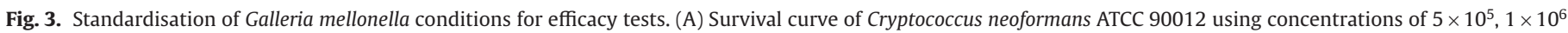
and $5 \times 10^{6}$ cells $/ \mathrm{mL}$. (B) Pedalitin (PED) toxicity using doses of 6.25, 12.5, 25, 40, 50, 100 and $200 \mathrm{mg} / \mathrm{kg}$. PBS, phosphate-buffered saline.

large amounts of yeast were observed in the untreated larvae infected with C. neoformans. Treatment with AmB $4 \mathrm{mg} / \mathrm{kg}$, PED $40 \mathrm{mg} /$ $\mathrm{kg}$ or the combination of these substances (AmB $0.3 \mathrm{mg} / \mathrm{kg}+\mathrm{PED}$ $10 \mathrm{mg} / \mathrm{kg}$ ) reduced the number of yeast. Fig. 5 shows the histopathology of untreated and treated larvae on the third day of the experiment, illustrating the high efficacy of these treatments.

\subsection{Efficacy of treatment with pedalitin alone and combined with amphotericin B in a murine model}

Treatment with AmB $1 \mathrm{mg} / \mathrm{kg}$, PED $40 \mathrm{mg} / \mathrm{kg}$ or the combination therapy of AmB $0.3 \mathrm{mg} / \mathrm{kg}+$ PED $10 \mathrm{mg} / \mathrm{kg}$ significantly prolonged the survival of mice $(P<0.05)$ compared with infected
A
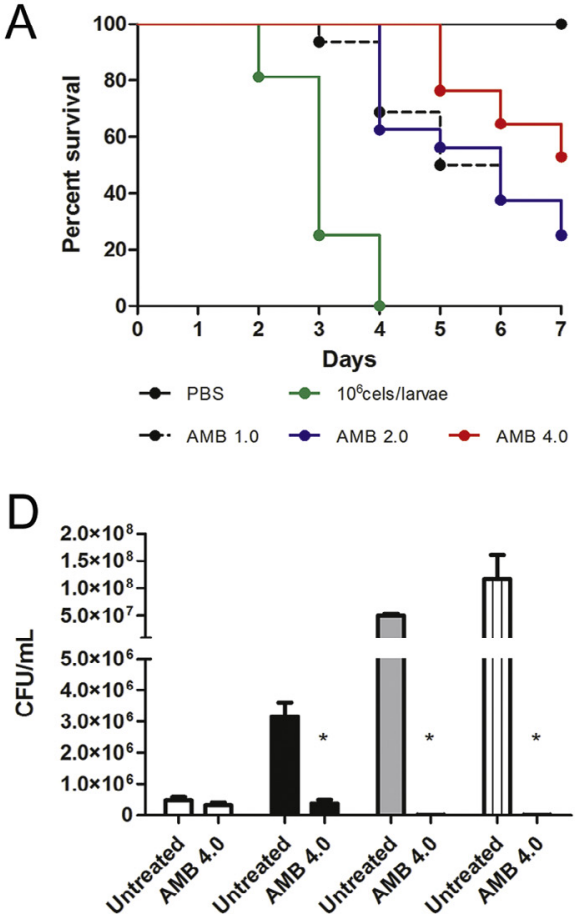

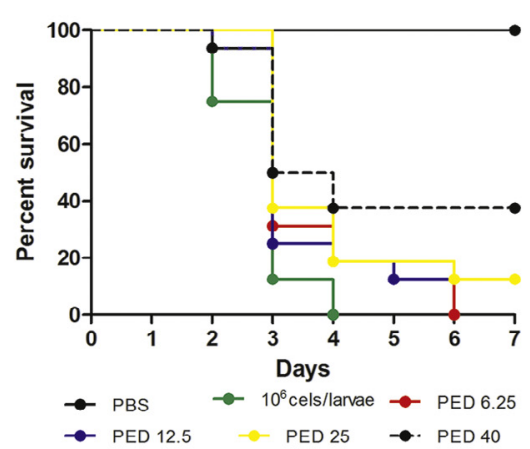

$\mathrm{E}$

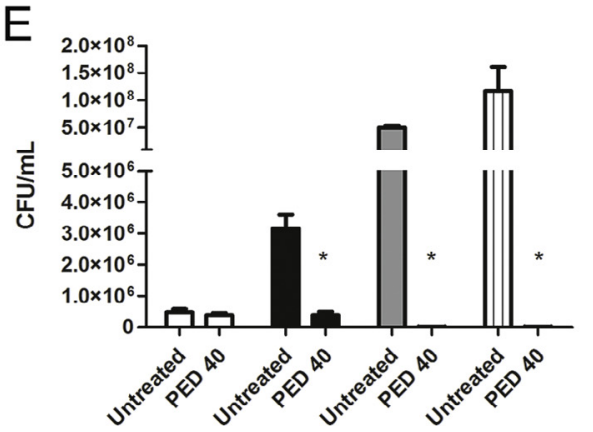

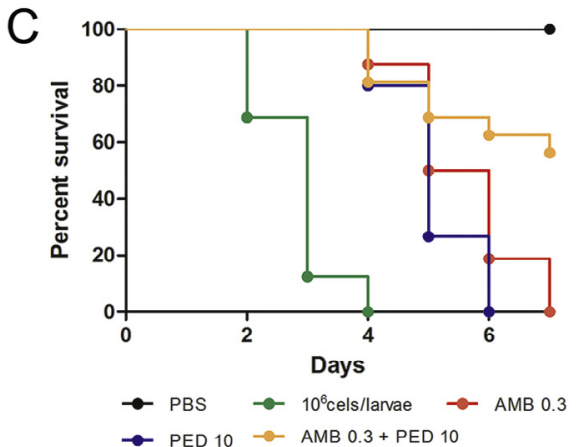

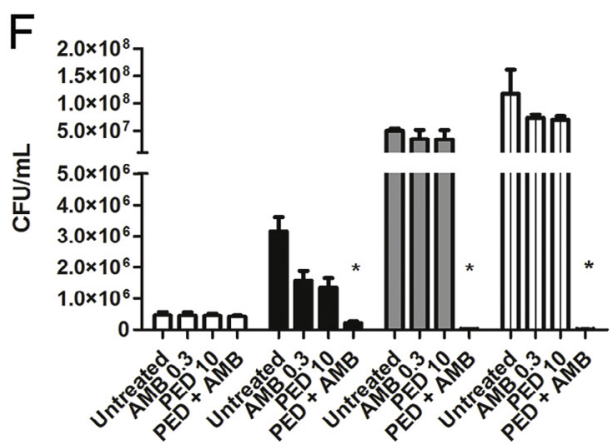

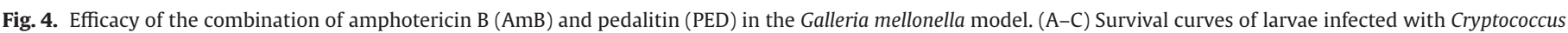

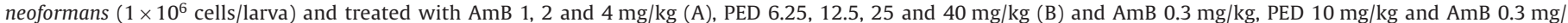

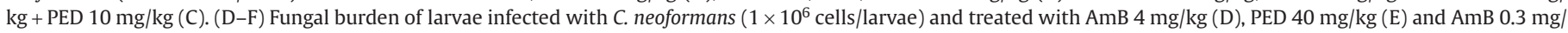
$\mathrm{kg}$, PED $10 \mathrm{mg} / \mathrm{kg}$ and AmB $0.3 \mathrm{mg} / \mathrm{kg}+$ PED $10 \mathrm{mg} / \mathrm{kg}$ (F). Colours represent Day 0 (white), Day 1 (black), Day 2 (grey) and Day 3 (striped). * P<0.001. 
Untreated

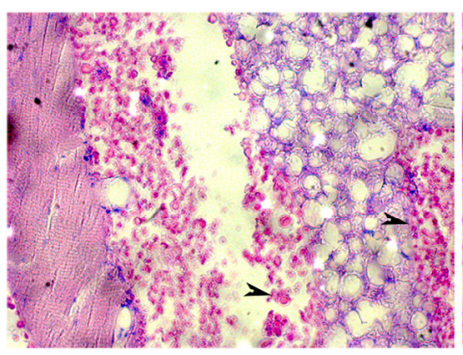

AMB

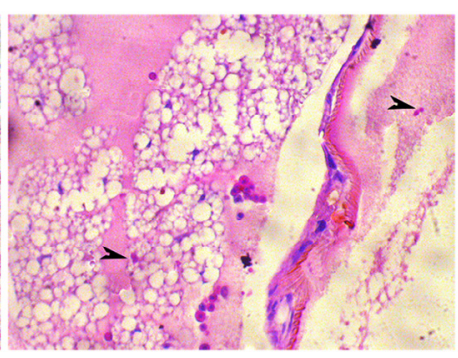

PED

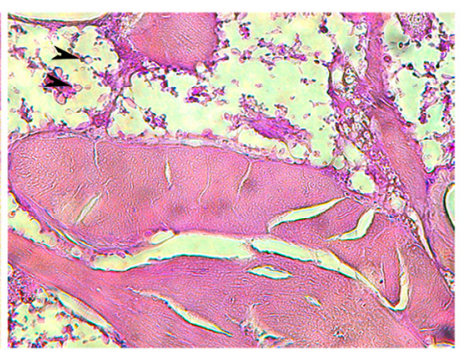

$\mathrm{PED}+\mathrm{AMB}$

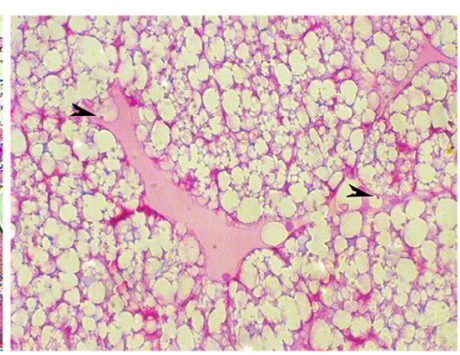

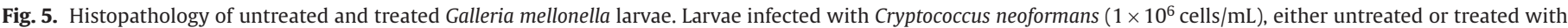

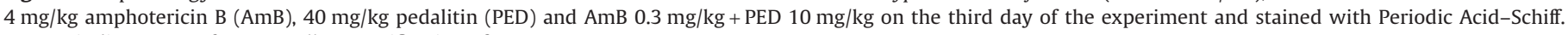
Arrows indicate C. neoformans cells. Magnification of $400 \times$.

and untreated mice. After 20 days and 40 days of the experiment, survival of $60 \%$ and $40 \%$ was observed with the combined therapy, respectively; moreover, no difference was observed between the treatments with the compounds alone at higher doses (Fig. 6).

A high fungal burden was observed in the lungs of untreated animals. Treatment with AmB, PED or the combination therapy significantly decreased the fungal burden in both organs. After 7 days of treatment, a significant reduction of $48 \%$ in the fungal burden of the lungs and brain was observed for all treatments (Fig. 7).
Moreover, after 14 days of treatment, a reduction of $>80 \%$ in the number of colonies was observed for all treatments for both organs.

For histopathology, mouse lungs were selected because this organ is the most strongly affected in cryptococcosis (Fig. 8). The histopathological findings revealed fungal cells with increased capsules. After 14 days of treatment with AmB, PED or combination therapy, a significant reduction was observed in the number of yeasts. These results indicate a higher efficiency of combination therapy compared with monotherapy.

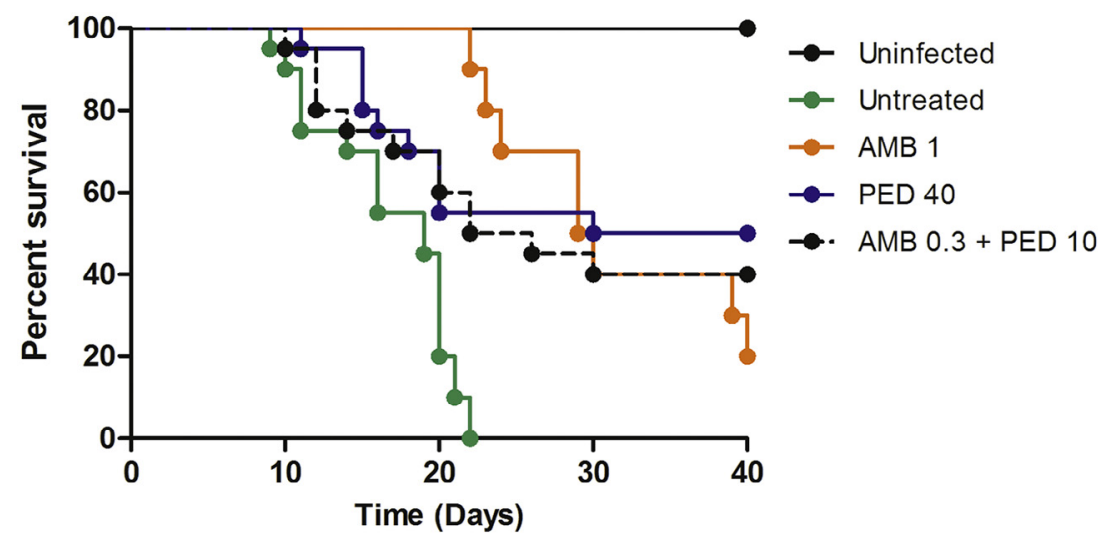

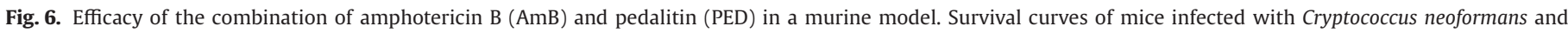
treated with $1 \mathrm{mg} / \mathrm{kg} \mathrm{AmB}, 40 \mathrm{mg} / \mathrm{kg}$ PED and AmB $0.3 \mathrm{mg} / \mathrm{kg}+$ PED $10 \mathrm{mg} / \mathrm{kg}$.
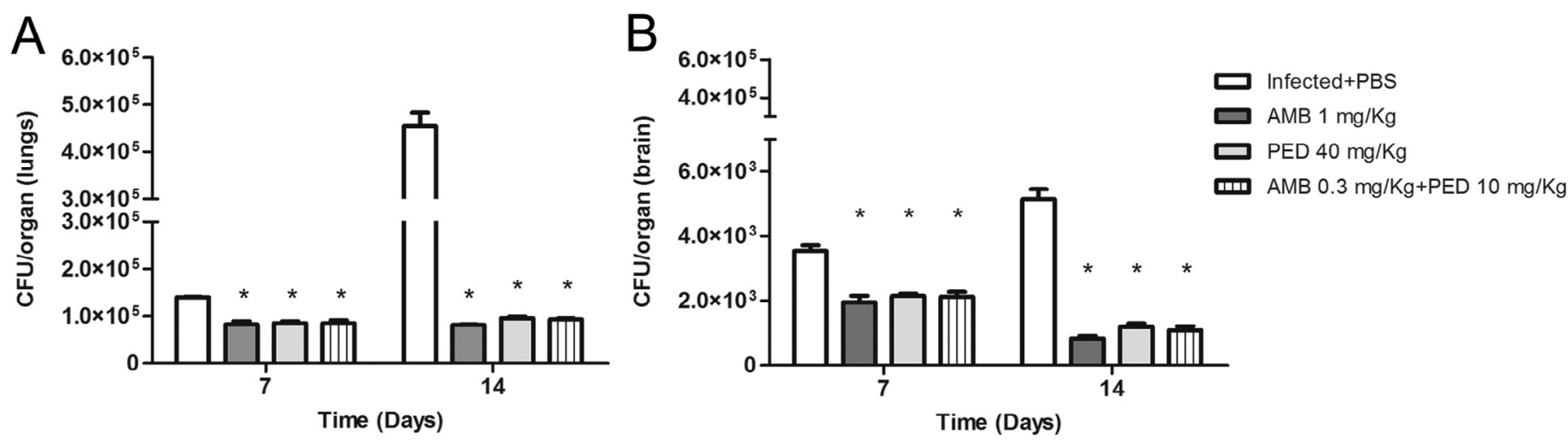

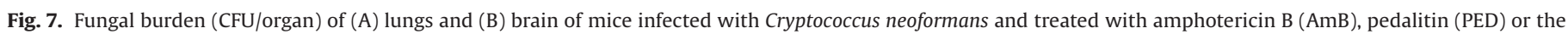
combination therapy. ${ }^{*} P<0.05$. Data are given as the mean \pm standard deviation. 

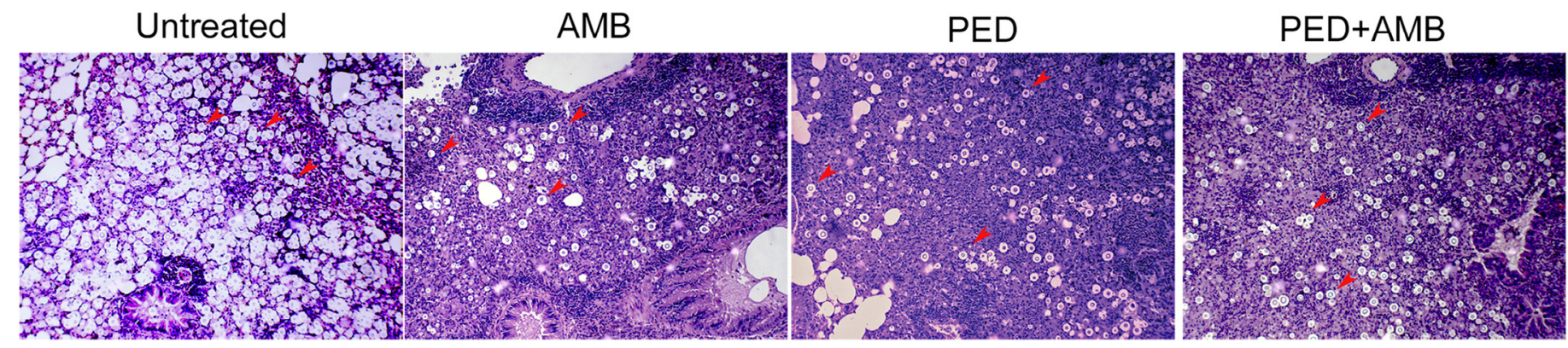

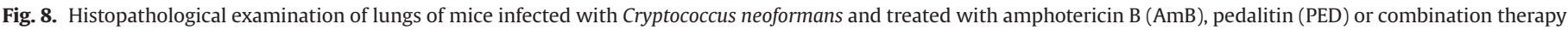
by haematoxylin and eosin staining. Arrows indicate C. neoformans cells. Magnification of $200 \times$.

\section{Discussion}

Because of the complications in the treatment of cryptococcosis, the study of plants and their derivatives as an alternative source of new antifungal compounds has been highlighted in recent years [26]. In vitro studies with PED showed antifungal activity against C. neoformans. Moreover, PED shows synergistic activity with AmB, reducing the necessary concentration of both substances by fourfold. PED also showed savings when the SI and $\mathrm{IC}_{50}$ were evaluated.

The combination of antifungal substances is a promising way to increase the percentage of successful treatment and reduces the required concentrations of the antifungals and consequently their toxicity [13]. Clinical isolates of $C$. neoformans were tested with combinations of $\mathrm{AmB}$ and different compounds resulting in a reduction of capsule induction [27]. Another study tested the combination of AmB and fluconazole against $C$. gattii strains resulting in synergistic to antagonistic activity depending on the strain and concentration tested [28].

In the current study, the effect of antifungal treatment on hostyeast interaction was analysed in MRC-5 and U87-MG cells. High inhibition of yeast-cell interaction was observed after treatment with the substances alone or in combination. Adhesion of pathogenic microorganisms to host tissues is considered indispensable for colonisation and progression of the infectious process, and the large number of tissues that fungi can colonise and infect suggests that they have a variety of surface molecules that allow the adhesion process [29].

To evaluate the in vitro efficiency, $C$. neoformans was subjected to treatments with PED, AmB and the combination treatment for different times ( $30 \mathrm{~min}$ to $48 \mathrm{~h}$ ). The fungicidal effect of the compounds was evaluated by time-kill during $48 \mathrm{~h}$ of exposure. Significant results were obtained after $8 \mathrm{~h}$ of exposure to the tested substances; after contact with AmB and PED both alone and in combination, the yeast death rate was $100 \%$. By comparison, Pereira de Sá et al. [30] evaluated the antifungal activity of 13 compounds against $C$. neoformans and $C$. gattii and selected 4 compounds. They conducted time-kill assays with these compounds and similar results to AmB were obtained. However, when the compounds were combined with AmB and/or fluconazole, no effect was found.

The G. mellonella model was used as an alternative animal for in vivo assays. Initially, G. mellonella was infected with different concentrations of $C$. neoformans, and $1 \times 10^{6}$ cells/larva was selected to correspond to a balance where not all larvae died at the beginning of the experiment but they also did not die too late. A previous study used a similar inoculum concentration [31]. Galleria mellonella has been used to evaluate the toxicity of compounds and solvents [32]. In the current study, doses of $>5 \%$ DMSO and doses $\geq 50 \mathrm{mg} /$ $\mathrm{kg}$ PED were not used in the efficacy experiments because they showed a toxic effect on larvae.

To evaluate the G. mellonella-C. neoformans in vivo efficacy of the combination of PED and AmB, three factors were evaluated: survival curve; fungal burden; and histological analysis. All doses of PED tested increased the survival of $C$. neoformans-infected larvae, and survival was highest for $40 \mathrm{mg} / \mathrm{kg}$. Regarding the PED and AmB combination, the treatment presented the same effect on larvae survival as high doses of these compounds alone ( $4 \mathrm{mg} / \mathrm{kg} \mathrm{AmB}$ or $40 \mathrm{mg} / \mathrm{kg}$ PED), indicating that the combination presents similar activity to the substances alone. A significant decrease in fungal burden was observed from macerated larvae and the histology images. The use of $G$. mellonella to verify in vivo antifungal efficacy and in vivo drug resistance has been reported for $C$. neoformans and other pathogenic fungi, and this alternative model appears appropriate for this purpose [33,34]. Galleria mellonella has also been described as an alternative animal model to screen new antifungal compounds [35,36].

After screening of the antifungal doses and evaluation of the synergistic combination efficacy using the alternative animal model $G$. mellonella, this effect was also evaluated in a murine model. As observed in G. mellonella, treatment with the combination of PED + AmB significantly increased the survival of the mice, and again the combined treatment was as efficient as AmB monotherapy at higher doses. Similar results were observed for the fungal burden and histopathological assays, proving the efficacy of this treatment. The correlation of fungal virulence and response to antifungal treatment between $G$. mellonella and mice has been described in different studies [37,38].

\section{Conclusion}

This study confirms the potential synergistic effect of combined therapy with PED and AmB against C. neoformans through various tests that validate the final results, again showing the effectiveness of the use of the G. mellonella alternative model as an excellent methodology for the optimisation of subsequent trials using the highly controversial murine model.

Funding: This work was supported by the following Brazilian organisations: FAPESP [2015/03700-9 (MJSMG); 2013/10917-9 (LS); 2015/14023-8 (HCO) and 2014/10446-9 (JLS)]; RENAMA-CNPq [403586/2012-7]; CAPES; and Programa de Apoio ao Desenvolvimento Científico da Faculdade de Ciências Farmacêuticas da UNESP (PADC/FCF).

Competing interests: None declared.

Ethical approval: All animal protocols were approved and performed in accordance with the guidelines established by the Institutional Animal Care and Use Committee Faculdade de Ciências Farmacêuticas, Universidade Estadual Paulista (UNESP) (Araraquara, Brazil) [CEUA/FCF/CAr no. 48/2012].

\section{References}

[1] Escandón P, de Bedout C, Lizarazo J, Agudelo CI, Tobón A, Bello S, et al. Cryptococcosis in Colombia: results of the national surveillance program for the years 2006-2010. Biomedica 2012;32:386-98. 
[2] Kwon-Chung KJ, Fraser JA, Doering TL, Wang Z, Janbon G, Idnurm A, et al. Cryptococcus neoformans and Cryptococcus gattii, the etiologic agents of cryptococcosis. Cold Spring Harb Perspect Med 2014;4:a019760.

[3] Lin YY, Shiau S, Fang CT. Risk factors for invasive Cryptococcus neoformans diseases: a case-control study. PLoS ONE 2015;10:e0119090.

[4] Prado M, Silva MB, Laurenti R, Travassos LR, Taborda CP. Mortality due to systemic mycoses as a primary cause of death or in association with AIDS in Brazil: a review from 1996 to 2006. Mem Inst Oswaldo Cruz 2009;104:513-21.

[5] Alanio A, Vernel-Pauillac F, Sturny-Leclère A, Dromer F. Cryptococcus neoformans host adaptation: toward biological evidence of dormancy. MBio 2015;6:pii: e02580-14.

[6] Perfect JR, Dismukes WE, Dromer F, Goldman DL, Graybill JR, Hamill RJ, et al. Clinical practice guidelines for the management of cryptococcal disease: 2010 update by the Infectious Diseases Society of America. Clin Infect Dis 2010;50:291-322.

[7] Hartland CL, Pu J, Krysan D, Didone L, Moquist PN, Dandapani S, et al. Discovery and evaluation of fungicidal anti-cryptococcal molecules. Probe reports from the NIH Molecular Libraries Program. Bethesda, MD: National Center for Biotechnology Information; 2015.

[8] Sheng C, Miao Z, Ji H, Yao J, Wang W, Che X, et al. Three-dimensional model of lanosterol $14 \alpha$-demethylase from Cryptococcus neoformans: active-site characterization and insights into azole binding. Antimicrob Agents Chemother 2009;53:3487-95.

[9] Newman DJ, Cragg GM, Snader KM. The influence of natural products upon drug discovery. Nat Prod Rep 2000;17:215-34.

[10] Regasini LO, Fernandes DC, Castro-Gamboa I, Silva DHS, Furlan M, da Silva Bolzani V. Constituintes químicos das flores de Pterogyne nitens (Caesalpinioideae) [Chemical constituents of the flowers of Pterogyne nitens (Caesalpinioideae)]. Quím Nova 2008;31:doi:10.1590/S0100-40422008000400018.

[11] Regasini LO, Vellosa JC, Silva DH, Furlan M, de Oliveira OM, Khalil NM, et al. Flavonols from Pterogyne nitens and their evaluation as myeloperoxidase inhibitors. Phytochemistry 2008;69:1739-44.

[12] Fernandes DC, Regasini LO, Vellosa JC, Pauletti PM, Castro-Gamboa I, Bolzani VS, et al. Myeloperoxidase inhibitory and radical scavenging activities of flavones from Pterogyne nitens. Chem Pharm Bull (Tokyo) 2008;56:723-6.

[13] Shao PL, Huang LM, Hsueh PR. Recent advances and challenges in the treatment of invasive fungal infections. Int J Antimicrob Agents 2007;30:487-95.

[14] Silva EG, Paula CR, de Assis Baroni F, Gambale W. Voriconazole, combined with amphotericin $\mathrm{B}$, in the treatment for pulmonary cryptococcosis caused by $C$. neoformans (serotype A) in mice with severe combined immunodeficiency (SCID). Mycopathologia 2012;173:445-9.

[15] Baddley JW, Pappas PG. Antifungal combination therapy: clinical potential. Drugs 2005;65:1461-80.

[16] Arora T, Mehta AK, Joshi V, Mehta KD, Rathor N, Mediratta PK, et al. Substitute of animals in drug research: an approach towards fulfillment of 4R's. Indian J Pharm Sci 2011;73:1-6

[17] Mylonakis E, Moreno R, El Khoury JB, Idnurm A, Heitman J, Calderwood SB, et al. Galleria mellonella as a model system to study Cryptococcus neoformans pathogenesis. Infect Immun 2005;73:3842-50.

[18] Trevijano-Contador N, Herrero-Fernández I, García-Barbazán I, Scorzoni L, Rueda C, Rossi SA, et al. Cryptococcus neoformans induces antimicrobial responses and behaves as a facultative intracellular pathogen in the non mammalian model Galleria mellonella. Virulence 2015;6:66-74.

[19] Clinical and Laboratory Standards Institute. Reference method for broth dilution antifungal susceptibility testing of yeasts; approved standard. 3rd ed. Wayne, PA: CLSI; 2008 Document M27-A3.

[20] Scorzoni L, Benaducci T, Fusco Almeida AM, Siqueira Silva DH, da Silva Bolzani V, Soares Mendes Gianinni MJ. The use of standard methodology for determination of antifungal activity of natural products against medical yeasts Candida sp and Cryptococcus sp. Braz J Microbiol 2007;38:391-7.

[21] White RL, Burgess DS, Manduru M, Bosso JA. Comparison of three different in vitro methods of detecting synergy: time-kill, checkerboard, and E test. Antimicrob Agents Chemother 1996;40:1914-18.

[22] Odds FC. Synergy, antagonism, and what the chequerboard puts between them. J Antimicrob Chemother 2003;52:1.

[23] Gullo FP, Sardi JC, Santos VA, Sangalli-Leite F, Pitangui NS, Rossi SA, et al. Antifungal activity of maytenin and pristimerin. Evid Based Complement Alternat Med 2012;2012:340787.

[24] Bézivin C, Tomasi S, Lohézic-Le Dévéhat F, Boustie J. Cytotoxic activity of some lichen extracts on murine and human cancer cell lines. Phytomedicine 2003;10:499-503.

[25] Zaragoza O, García-Rodas R, Nosanchuk JD, Cuenca-Estrella M, Rodríguez-Tudela JL, Casadevall A. Fungal cell gigantism during mammalian infection. PLoS Pathog 2010;6:e1000945.

[26] Regasini LO, Pivatto M, Scorzoni L, Benaducci T, Fusco-Almeida AM, Soares Mendes Giannini MJ, et al. Antimicrobial activity of Pterogyne nitens Tul., Fabaceae, against opportunistic fungi. Rev Bras Farmacogn 2010;20:70611.

[27] Rossato L, Loreto É, Venturini TP, Azevedo MI, Weiblen C, Botton SA, et al. In vitro interaction of antifungal and antibacterial drugs against Cryptococcus neoformans var. grubii before and after capsular induction. Med Mycol 2015;53:885-9.

[28] Santos JR, Gouveia LF, Taylor EL, Resende-Stoianoff MA, Pianetti GA, César IC, et al. Dynamic interaction between fluconazole and amphotericin B against Cryptococcus gattii. Antimicrob Agents Chemother 2012;56:2553-8.

[29] da Silva Castro N, Barbosa MS, Maia ZA, Báo SN, Felipe MS, Santana JM, et al. Characterization of Paracoccidioides brasiliensis PbDfg5p, a cell-wall protein implicated in filamentous growth. Yeast 2008;25:141-54.

[30] Pereira de Sá N, Lino CI, Fonseca NC, Borelli BM, Ramos JP, Souza-Fagundes EM, et al. Thiazole compounds with activity against Cryptococcus gattii and Cryptococcus neoformans in vitro. Eur J Med Chem 2015;102:233-42.

[31] García-Rodas R, Casadevall A, Rodríguez-Tudela JL, Cuenca-Estrella M, Zaragoza O. Cryptococcus neoformans capsular enlargement and cellular gigantism during Galleria mellonella infection. PLoS ONE 2011;6:e24485.

[32] Megaw J, Thompson TP, Lafferty RA, Gilmore BF. Galleria mellonella as a novel in vivo model for assessment of the toxicity of 1-alkyl-3-methylimidazolium chloride ionic liquids. Chemosphere 2015;139:197-201.

[33] Forastiero A, Bernal-Martínez L, Mellado E, Cendejas E, Gomez-Lopez A. In vivo efficacy of voriconazole and posaconazole therapy in a novel invertebrate model of Aspergillus fumigatus infection. Int J Antimicrob Agents 2015;46:511-17.

[34] Scorzoni L, de Lucas MP, Mesa-Arango AC, Fusco-Almeida AM, Lozano E, Cuenca-Estrella M, et al. Antifungal efficacy during Candida krusei infection in non-conventional models correlates with the yeast in vitro susceptibility profile. PLOS ONE 2013;8:e60047.

[35] Browne N, Hackenberg F, Streciwilk W, Tacke M, Kavanagh K. Assessment of in vivo antimicrobial activity of the carbene silver(I) acetate derivative SBC3 using Galleria mellonella larvae. Biometals 2014;27:745-52.

[36] Rowan R, Moran C, McCann M, Kavanagh K. Use of Galleria mellonella larvae to evaluate the in vivo anti-fungal activity of $\left[\mathrm{Ag}_{2}(\mathrm{mal})(\mathrm{phen})_{3}\right]$. Biometals 2009;22:461-7.

[37] Brennan M, Thomas DY, Whiteway M, Kavanagh K. Correlation between virulence of Candida albicans mutants in mice and Galleria mellonella larvae. FEMS Immunol Med Microbiol 2002;34:153-7.

[38] Desalermos A, Tan X, Rajamuthiah R, Arvanitis M, Wang Y, Li D, et al. A multi-host approach for the systematic analysis of virulence factors in Cryptococcus neoformans. J Infect Dis 2015;211:298-305. 